\title{
DETECTING FINANCIAL SUSTAINABILITY RISK OF THE ASSETS USING MAMDANI FUZZY CONTROLLER
}

\author{
Marcel-Ioan BOLOȘ ${ }^{1}$, Ioana-Alexandra BRADEA ${ }^{2}$, \\ Claudia Diana SABĂU-POPA (D ${ }^{*}$, Laurențiu-Andrei ILIE ${ }^{4}$ \\ ${ }^{1,3}$ Department of Finance-Accounting, Faculty of Economic Sciences, \\ University of Oradea, Oradea, Romania \\ ${ }^{2}$ Department of Informatics and Economic Cybernetics, \\ Bucharest University of Economic Studies, Bucharest, Romania \\ ${ }^{4}$ Faculty of Geography, University of Bucharest, Bucharest, Romania
}

Received 13 October 2018; accepted 05 May 2019

\begin{abstract}
The paper aims to develop a MAMDANI fuzzy controller for detecting the financial sustainability risk of the assets owned by the company. This type of risk indicates when an asset no longer produces economic benefits to the company, or the benefits are small enough to no longer justify the asset maintaining in working order. The proposed fuzzy controller has as input variables the asset operating expenses and the variation of this category of expenses from one analysis period to another. The controller's objective function is to keep operating costs at their initial state and thus reducing the financial sustainability risk. The controller's output variable is represented by the economic benefits variation, considered to be an essential component in the financial sustainability risk analysis. The obtained results were interpreted taking into account the objective function of the controller as well as the evolution of the input variables. Two simulations for fuzzy controllers were made, with the mention that the variation ranges for the input variables were delimited. In practice, fuzzy controllers can be generated according to company policies to keep under control the expense categories that accompany the asset exploitation.
\end{abstract}

Keywords: MAMDANI fuzzy controller, financial sustainability risk, assets, simulation.

JEL Classification: C63, G32.

\section{Introduction}

The company's decision to invest in tangible assets represents a complex process that involves long-term capital assets. The cost of capital assets is often quite significant, especially when this capital comes from financial creditors. That is why the investment decision process must take into account the profitability of the capital invested in assets regardless of their nature. Profitability as an indicator is demanded intensely by shareholders, as well as by the financial

*Corresponding author. E-mail: dianasabaupopa@yahoo.ro 
institutions which are interested in recovering their capital as quickly as possible and with minimum risk.

By their content, the economic benefits, for each tangible asset, are a source of "added value", from which the financial creditors are remunerated on the basis of the interest paid by the company and shareholders can also be paid with dividends. Every purchased asset is a carrier of "added value" for the company and contributes to the company's financial wealth, for example for the emergence of the gross surplus before interest, taxes and depreciation known as EBITDA.

The acquisition of a tangible asset becomes a management decision where not only the asset acquisition cost, but also its economic performance, matters. The asset economic performance depends on the different technical parameters such as: production capacity, asset running costs, maintenance costs, and so on. The best combination of the acquisition cost and their economic performance builds on the process of asset acquisition under economic efficiency. Economic benefits are the result of the assets economic performance, between them being a direct proportionality relationship. Thus, the economic performance can determine economic benefits and return on investments duration compatible with shareholders expectations.

Regardless of the studies and analyzes on which the asset acquisition process is based, three elements are important in the decision making process, namely:

The assets acquisition cost that determines the amount of financial resources to be disposed of in the investments made by the company and which must then be recovered in a limited time. If the financing source is a bank loan, then interest should be taken into account also as a cost item.

The asset economic performance depends on the technical and economic parameters. They are set up with the initial purchase of assets. Economic performance has a direct impact on economic benefits generated by assets.

The asset economic benefits are dependent on the initial economic performance of assets. They have direct impact on the recovery investment rate.

Regardless the combination of acquisition cost, economic performance and benefits, the financial sustainability represent an indicator of asset behavior analysis, which is important throughout the assets life cycle. Thus, it is important to establish through financial sustainability the moment when the tangible asset no longer produces the economic benefits that underpin its maintenance in company.

\section{Literature review}

The literature has advanced the idea that a tangible asset should no longer be regarded as a capital asset for a limited period of time and therefore as a cost element that irreversibly depreciates (Ambrose \& Megginson, 1992). A tangible asset becomes a capital asset that is expected to produce economic benefits to the company and its acquisition cost can be reliably measured. (Ardeleanu-Popa \& Miheş, 2007)

It was introduced a new notion for tangible assets that is very important for the decisionmaking process, namely the economic benefits that result from the assets participation in the company's operational activity (Galbreath, 2005; Bolos \& Sabau-Popa, 2017). 
The use of fuzzy techniques for analyzing the assets financial sustainability in a company has been less studied, even if the applicability and efficiency of fuzzy methods for solving multi-criteria group decision making problems were demonstrated in different research area (Krishankumar et al., 2018).

On the other hand the MAMDANI fuzzy controller has captured the interest of the researchers, according to Web of Science database, 651 ISI articles being published over time, but none of them targeted the economic area, most of them being framed in the following research areas: computer science, engineering, automation control systems, robotics and mathematics. Thus, this type of fuzzy controller was applied in: industry, for designing fuzzy control systems focused on industrial applications (Precup \& Hellendoorn, 2011; Huang et al., 2018); nonlinear dynamics, for developing new learning laws for Mamdani and other type fuzzy neural networks based on input-to-state stability approach (Yu \& Li, 2004; Mann, Hu, \& Gosine, 1999); designing genetic fuzzy systems that manage the interpretability-accuracy tradeoff (Cordon, 2011); uncertainty management (Wu, Z. Yang, Wang, Li, \& Y. Yang, 2018), or approximating real continuous control functions on a compact set to arbitrary accuracy (Galichet \& Foulloy, 1995).

The most cited studies focused on engineering domain. Wang, Chen, and Dai (2007) proposed a direct adaptive fuzzy tracking control for a class of perturbed strict-feedback nonlinear systems, with unknown virtual control coefficients. Their architecture illustrated that all the signals in the resulting closed-loop system are uniform bounded and the tracking error converges to an arbitrarily small neighborhood of the origin. Another relevant study in this field developed a new method that uses the Kalman filter to optimize a Mamdani fuzzy PID controller (Ahn \& Truong, 2009). The hybrid model adjusts the controller parameters automatically during the operation process of any system applying the controller to minimize the control error.

The analysis of analytical structure and stability of a fuzzy PID controller was conducted by Mohan and Sinha (2008) in order to demonstrate the effectiveness of the simplest fuzzy PID controller in different area. Qin, Sun, Hua, and Liu (2018) managed to improve the PID controller performance based on fuzzy logic by identifying a linear model based on the least squares method, optimizing the PID parameters and designing a fuzzy adaptive PID controller based on these parameters.

Regarding company's investment decision in assets, Mannasoo and Maripuu (2015) studied its influence on performance. They divided this decision in short-term investments in current assets and long-term productivity-enhancing investments in tangible and intangible assets and discovered that there are patterns influenced by macroeconomic fluctuations with impact on the company's financial strength and sustainability. On the other hand, Harris (2017) studied how to increase sustainability through assets management.

The relationship between strategies and the assets conditions was studied by Liu, Chen, and Xie (2018). Using a sustainability analysis, this study tried to establish the incidence mechanism of assets on strategies.

Reichardt (2006) analyzed how companies grow by acquisition and conduct due diligence assessments in order to identify the opportunities and risks associated with potential acquisitions of new assets. He highlights the limitations of conventional assessments based 
solely on financial risk and presents practical recommendations on structuring due diligence assessments to consider the full risk profile and the lifecycle of an asset.

This paper targets to propose a fuzzy method in which asset regardless of their nature is analyzed based on the financial sustainability risk defined as the risk category, in which the company's investments in that asset are no longer warranted from the economic efficiency point of view.

\section{The concept of assets financial sustainability}

The assets financial sustainability has been studied in the literature through various models, each of which has as a common element, namely the establishment of the optimal moment of putting the asset out of use. Determining this time point $(T)$ represents a complex decision that must take into account the fact that another asset must replace the original asset, which in turn involves costs. The analysis model for replacing an asset, or for determining the optimal moment of decommissioning, is the one that conceptually analyzes assets as a source of cash-flow generator.

The cash flow generated by an asset is based on a few basic elements, namely:

The asset production capacity $(Q)$ based on its economic performance, on which depends the value of the output obtained with the help of the asset per unit of time. The output obtained with the assets will have a certain unitary cost of production $\left(C_{u}\right)$, a profit margin $\left(r_{\pi}\right)$ and a selling price $(p)$. In these conditions the volume of production is determined by the production capacity and the sale price of the goods obtained by the form: $\sum Q \times p$.

The asset operating costs $\left(C_{h f}\right)$ take different forms: from the utilities cost necessary for its operation up to specific costs for the assets operation. All these costs depend on the dynamics of the asset's operation but also on how it is used in the production process.

Maintenance costs $\left(C h_{m e n}\right)$ are expenditures required to maintain the asset's operating condition, which in turn depends on the frequency of failures, the asset maintenance plan, and the time required for its technical revisions.

Theorem no. 1: Any asset that is used in the operational activity of a company generates a total cash-flow over the life cycle of that asset $[0, T]$, of the form:

$$
V_{t}=\int_{0}^{T}\left[V_{a}(t)-C h_{a}(t)\right] \times e^{-i t}+V R_{a}(t) \times e^{-i T}-I .
$$

Demonstration: The annual cash flows for the life of the asset $[0 ; \mathrm{T}]$ is formed from the difference between the income generated by an asset $\left(V_{a}\right)$ and its total operating and maintenance expenses $\left(C h_{a}\right)$ :

$$
\begin{aligned}
& t_{0}: V_{a}\left(t_{0}\right)-C h_{a}\left(t_{0}\right) \times \frac{1}{\left(1+r_{a}\right)^{0}} \\
& t_{1}: V_{a}\left(t_{1}\right)-C h_{a}\left(t_{1}\right) \times \frac{1}{\left(1+r_{a}\right)^{1}} ; \\
& t_{n}: V_{a}\left(t_{n}\right)-C h_{a}\left(t_{n}\right) \times \frac{1}{\left(1+r_{a}\right)^{n}} .
\end{aligned}
$$


The present value of the future cash flows determined by the asset operation over its entire life cycle will be as follows:

$$
V_{T}=\left(V_{a}\left(t_{n}\right)-C h_{a}\left(t_{n}\right)\right) \times\left(\frac{1}{\left(1+r_{a}\right)^{0}}+\frac{1}{\left(1+r_{a}\right)^{1}}+\ldots+\frac{1}{\left(1+r_{a}\right)^{n}}\right) .
$$

If $r_{a}$ is the same, than $\lim _{n \rightarrow \infty} \sum_{i=1}^{n} \frac{1}{\left(1+r_{a}\right)^{n}} \rightarrow e^{-i t}$.

The amount of operational cash flows generated by the company's assets over their life cycle will be written as:

$$
V_{t G r o s s}=\int_{0}^{T}\left[V_{a}(t)-C h_{a}(t)\right] \times e^{-i t} .
$$

The operational cash flows are important because they contribute to generate "added value" across the company. If from the cash flow value is deducted the acquisition value of the asset $(\mathrm{I})$ and is added the residual value $\left(V R_{a}\right)$ is obtained the value of the total cash flow generated by an active during its lifetime.

$$
V_{t N e t}=\int_{0}^{T}\left[V_{a}(t)-C h_{a}(t)\right] \times e^{-i t}+V R_{a}(t) \times e^{-i T}-I .
$$

The company is interested in determining the economic life of the assets, the period on which they will invest in tangible assets in terms of economic efficiency. During the economic life of assets, the economic benefits have a logarithmic evolution, being initially higher, after which, with the passage of time, they begin to decrease as a result of the increase in main-

tenance or operating expenses.
The economic benefits over the lifetime of the asset: $B_{e}=\int_{0}^{T}\left[V_{a}(t)-C h_{a}(t)\right] \times e^{-i t}$ represent the most important indicator providing information about the economic life of an asset. When the cumulative economic benefits are equal to the cost of the tangible asset, the asset's economic lifetime has been reached. Beyond that time, the operation cost of the asset will generate low-value of economic benefits or even losses, that no longer justify keeping it in working order.

Theorem no. 2: The economic life of an asset is determined by the operating cash flow of the asset and its discount rates according to the formula:

$$
T^{*}=\frac{V_{a 0}-C h_{a 0}-i V R_{a}(t)}{r_{c h a}-r_{v a}}[\text { years }] .
$$

Demonstration: The economic lifetime is obtained with the first-order derivative in relation to $\mathrm{T}$ for the total cash-flow equation, namely:

$$
\frac{\partial V_{t}}{\partial T}=0
$$

By performing the calculations, we obtain:

or

$$
\left[V_{a}(t)-C h_{a}(t)\right] \times e^{-i T}-i V R_{a}(t) \times e^{-i T}+V R_{a}^{\prime}(t) \times e^{-i T}=0
$$

$$
\left[V_{a}(t)-C h_{a}(t)\right]-i V R_{a}(t)+V R_{a}^{\prime}(t)=0 .
$$


In determining the optimum asset lifetime or the duration in which the value of the economic benefits equals the cost of the investment, the following assumptions are made:

Hypothesis no. 1: Income generated by tangible assets has an annual actualization rate $\left(r_{v a}\right)$ and total expenses have an annual actualization rate $\left(r_{c h a}\right)$ that is recorded over the life of assets:

- for the operational income of the asset: $V_{a}(t)=V_{0}\left(1+r_{v a}\right)^{t}$;

- for the operational expenses of the asset: $C h_{a}(t)=C h_{0}\left(1+r_{c h a}\right)^{t}$.

Hypothesis no. 2: The remaining value of the asset is dependent on its decreasing depreciation during $[0, \mathrm{~T}]$, of the form:

$$
V R_{a}(t)=I e^{\frac{-i T}{4}} \mathrm{cu} V R_{a}^{\prime}(t)=-\frac{i}{4} I e^{\frac{-i T}{4}} .
$$

Considering the residual value of the asset as a market-dependent constant at time $T$, it is obtained after solving the equation: $\left[V_{a}(t)-C h_{a}(t)\right]-i V R_{a}(t)+V R_{a}^{\prime}(t)=0$ the following expression for determining $T$ :

$$
T^{*}=\frac{V_{a 0}-C h_{a 0}-i V R_{a}(t)}{r_{c h a}-r_{v a}}[\text { years }] .
$$

In practice, a number of models have been developed to determine the optimal replacement time for an asset, such as: the annual average cost of the machine (Kaufmann, 1963), the equivalent annual cost minimization method, the minimal negative method (Terborgh, 1949), the replacement algorithm, the cost minimization model, models based on finite-horizon technical progress, or models based on Pontryagin principle (Pontryagin, Boltyanskii, Gamkrelidze, \& Mishchenko, 1962). All these models aim to determine the optimal moment for replacing the asset motivated by the fact that the actual investment is no longer efficient. Almost all of these models are based on the concepts of: financial asset sustainability based on asset-generated cash flow, the residual value and the initial investment cost.

\section{The concept of financial sustainability risk}

Is there a risk of financial sustainability? The answer to this question is affirmative as long as the economic benefits of the asset are the result of the influence of external factors such as the tear of the asset, the evolution of technical progress, the technical condition of the asset and the examples could continue. The financial sustainability risk of an asset indicates the situation where any assets investment, whatever its nature, can generate losses for the company's economic activity. These categories of assets cause deterioration in economic benefits and may generate long-term losses for the company. For any assets investment is risen the question of the return on investment. The basic condition for identifying the financial sustainability risk of an asset, when the amounts are discrete, is that the net present value of the benefit plus the residual value of the asset must be equal to the cost of its initial investment after a relationship of the form:

$$
\left[V_{a}(t)-C h_{a}(t)\right] \times \frac{1}{\left(1+r_{a}\right)^{t}}+\frac{V R_{a}(t)}{\left(1+r_{a}\right)^{T}}=I .
$$


Starting from the basic condition of financial sustainability, the financial sustainability risk $\left(R_{s f}\right)$ can be quantified, for discrete values, as:

$$
R_{s f}=\frac{\left[V_{a}(t)-C h_{a}(t)\right] \times \frac{1}{\left(1+r_{a}\right)^{t}}+\frac{V R_{a}(t)}{\left(1+r_{a}\right)^{T}}}{I} \times 100[\%] .
$$

For continuous values, the financial sustainability risk of an asset can be quantified as:

$$
R_{s f}=\frac{\int_{0}^{T}\left[V_{a}(t)-C h_{a}(t)\right] \times e^{-i t}+V R_{a}(t) \times e^{-i T}}{I} \times 100[\%] .
$$

From the quantification of the financial sustainability risk, it is clear that an essential component of the risk is the economic benefit generated by the asset. Thus, high economic benefits will result in: optimal economic life for assets that are compatible with the expectations of the company's shareholders and controllable values for sustainability risk. Small economic benefits will generate long economic lifetimes that can cause the replacement of the asset due to the fact that it is no longer a source of added value for the company, and hence generates high values for the financial sustainability risk. What is relevant for the financial sustainability risk is the influence of operational and maintenance costs on the economic benefits. These spending categories directly affect the level of economic benefits and the financial sustainability risk.

Highlighting the impact of these spending categories on the economic benefits generated by companies' assets can be achieved by the economic elasticity coefficient $\left(e_{b e}\right)$ established according to the variance in economic benefits $(\Delta B e)$, as well as the variation in operating expenses $\left(\Delta C h_{a}\right)$ after a relationship of the form:

There are several situations, namely:

$$
e_{b e}=\frac{\frac{\Delta B e}{B e}}{\frac{\Delta C h_{a}}{C h_{a}}}
$$

1) If $e_{b e} \rightarrow 1$, most of the economic benefit is influenced by the variation in the assets operating and maintenance costs and hence the exposure to financial sustainability risk is increased.

2) If $e_{b e} \rightarrow 0$, there is a slight influence of the assets operation and maintenance costs on the economic benefits and therefore the exposure to financial sustainability risk is low.

Regardless of the form of the financial sustainability risk and its quantification, it is important to determine the impact of this category of risk on the economic life of an asset. Once the financial sustainability risk has been manifested, especially when it has values close to 1 , it is important to determine whether the investment in the asset continues or it is necessary its replacement.

\section{The Mamdani Fuzzy Controller to detect the assets financial sustainability risk}

The MANDAMI fuzzy controller has been built around the elasticity coefficient that best reflects the financial sustainability risk. The first step in designing the fuzzy controller is to 
identify the input fuzzy variables that will be set as the objective function, as well as the output variable for each is tracked the impact on it when the input variables varies. The input variables of the MAMDANI fuzzy controller are:

a) The asset operating and maintenance costs $\left(C h_{a}\right)$ are expressed as a percentage of the asset's value using the following linguistic terms shown in the Table 1:

Table 1 . The linguistic terms and the variation range of the fuzzy variable - operating costs

\begin{tabular}{|l|l|l|}
\hline \multicolumn{1}{|c|}{ Linguistic terms } & \multicolumn{1}{|c|}{ Symbol } & \multicolumn{1}{c|}{ Variation range } \\
\hline $\begin{array}{l}\text { Operating costs } \\
\text { NEGATIVE }\end{array}$ & $C h_{a} N$ & $0 \% \div\left(-p C h a \%^{*}\right)$ \\
\hline $\begin{array}{l}\text { Operating costs } \\
\text { ZERO }\end{array}$ & $C h_{a} Z$ & $0 \%$ \\
\hline $\begin{array}{l}\text { Operating costs } \\
\text { POSITIVE }\end{array}$ & $C h_{a} P$ & $0 \% \div\left(+p C h a \%^{*}\right)$ \\
\hline
\end{tabular}

Note: ${ }^{*}-p C h a \%=\frac{C h a}{V_{a}} \times 100-$ the percentage of expense in the asset value.

b) The variance of the asset operating costs $\left(\Delta C h_{a}\right)$ being expressed as percentage changes from one analysis period to the another, using the following linguistic terms (Table 2):

Table 2. The linguistic terms and the variation range of the fuzzy variable - operating cost variation

\begin{tabular}{|l|c|c|}
\hline \multicolumn{1}{|c|}{ Linguistic terms } & Symbol & Variation range \\
\hline $\begin{array}{l}\text { Operating cost variation } \\
\text { NEGATIVE }\end{array}$ & $\Delta C h_{a} N$ & $0 \% \div\left(-p \Delta C h a \%{ }^{*}\right)$ \\
\hline $\begin{array}{l}\text { Operating cost variation } \\
\text { ZERO }\end{array}$ & $\Delta C h_{a} Z$ & $0 \%$ \\
\hline $\begin{array}{l}\text { Operating cost variation } \\
\text { POSITIVE }\end{array}$ & $\Delta C h_{a} P$ & $0 \% \div\left(+p \Delta C h a \%{ }^{*}\right)$ \\
\hline
\end{tabular}

Note: ${ }^{*}-p \Delta C h a \%=\frac{C h a_{t+1}}{C h a_{t}} \times 100-$ the variation cost from one period to another.

c) The output variable is the economic benefits variation $(\Delta B e)$ when there is a change in operating expenses from one period to another. It is determined their impact on the change in net benefits expressed in linguistic terms (Table 3):

Table 3. The linguistic terms and the variation range of the fuzzy variable - the economic benefits variation

\begin{tabular}{|l|c|c|}
\hline \multicolumn{1}{|c|}{ Linguistic terms } & Symbol & Variation range \\
\hline $\begin{array}{l}\text { The economic benefits variation } \\
\text { NEGATIVE }\end{array}$ & $\Delta B e N$ & $0 \% \div\left(-p \Delta B e^{*}\right)$ \\
\hline $\begin{array}{l}\text { The economic benefits variation } \\
\text { ZERO }\end{array}$ & $\Delta B e Z$ & $0 \%$ \\
\hline $\begin{array}{l}\text { The economic benefits variation } \\
\text { POSITIVE }\end{array}$ & $\Delta B e P$ & $0 \% \div\left(+p \Delta C h a \%{ }^{*}\right)$ \\
\hline
\end{tabular}

Note: ${ }^{*}-p \Delta B e \%=\frac{B e_{t+1}}{B e_{t}} \times 100-$ the economic benefits variation from one period to another. 
The second step is to establish the rules base of the fuzzy controller. For this, it starts from the objective function of the fuzzy controller, which is the deviations minimization from the initial asset operating costs for its life cycle, of the form:

$$
e\left(C h_{a}\right)=C h_{a}^{*}-C h_{a}(k) \rightarrow 0 .
$$

This means that any deviation from the initial operating costs $\left(C h_{a}^{*}\right)$ will cause a deviation of the asset's economic benefits that are mostly influenced by the income generated by the asset (Table 4).

Table 4 . The fuzzy rule base of the controller

\begin{tabular}{|c|c|c|c|}
\hline$\Delta e\left(C h_{a}\right)$ & $\left.C h_{a}\right)$ & $C h_{a} Z$ & $C h_{a} P$ \\
\hline$\Delta C h_{a} N$ & $N$ & $N$ & $Z$ \\
\hline$\Delta C h_{a} Z$ & $N$ & $Z$ & $P$ \\
\hline$\Delta C h_{a} P$ & $Z$ & $P$ & $P$ \\
\hline
\end{tabular}

Rule no. 1:

$e\left(C h_{a}\right)=C h_{a}^{*}-C h_{a}(k)$ is $N \rightarrow C h_{a}^{*}-C h_{a}(k)\left\langle 0 \rightarrow C h_{a}(k)\right\rangle C h_{a}^{*}$;

$\Delta e\left(C h_{a}\right)=\left(C h_{a}^{*}-C h_{a}(k)\right)-\left(C h_{a}^{*}-C h_{a}(k-1)\right)<0$ is $N \rightarrow C h_{a}(k-1)-C h_{a}(k)<0$

and $C h_{a}(k)>C h_{a}(k-1)$.

Conclusion: $C h_{a}(k)$ records an increase value at time $(k)$ versus time $(k-1)$ and is higher than the initial reference expense $C h_{a}^{*}$. This means that the impact of this increase will cause a reduction in economic benefits, which means $B_{e}(k)<B_{e}(k-1)$ and hence $\Delta B_{e}(k)<N$.

Rule no. 2:

$$
\begin{aligned}
& e\left(C h_{a}\right)=C h_{a}^{*}-C h_{a}(k) \text { is } N \rightarrow C h_{a}^{*}-C h_{a}(k)\left\langle 0 \rightarrow C h_{a}(k)\right\rangle C h_{a}^{*} ; \\
& \Delta e\left(C h_{a}\right)=\left(C h_{a}^{*}-C h_{a}(k)\right)-\left(C h_{a}^{*}-C h_{a}(k-1)\right)=0 \text { is } Z \rightarrow C h_{a}(k-1)-C h_{a}(k)=0 \\
& \text { and } C h_{a}(k)=C h_{a}(k-1) .
\end{aligned}
$$

Conclusion: $\mathrm{Ch}_{a}(k)$ has the same value at time $(k)$ as in moment $(k-1)$ and is greater than the initial operating cost $C h_{a}^{*}$. This means that the impact of this increase will cause a reduction in economic benefits, which means that $B_{e}(k)<B_{e}(k-1)$ and hence $\Delta B_{e}(k)<N$.

Rule no. 3:

$$
\begin{aligned}
& e\left(C h_{a}\right)=C h_{a}^{*}-C h_{a}(k) \text { is } N \rightarrow C h_{a}^{*}-C h_{a}(k)\left\langle 0 \rightarrow C h_{a}(k)\right\rangle C h_{a}^{*} ; \\
& \Delta e\left(C h_{a}\right)=\left(C h_{a}^{*}-C h_{a}(k)\right)-\left(C h_{a}^{*}-C h_{a}(k-1)\right)>0 \text { is } P \rightarrow C h_{a}(k-1)-C h_{a}(k)>0 \\
& \text { and } C h_{a}(k)<C h_{a}(k-1) .
\end{aligned}
$$

Conclusion: $C h_{a}(k)$ records a decrease value at time $(k)$ from time $(k-1)$ and is higher than the initial reference expense $C h_{a}^{*}$. This means that the impact of this increase will result in a maintenance of the economic benefits, which means that $B_{e}(k)=B_{e}(k-1)$ and hence $\Delta B_{e}(k)=Z$. 
Rule no. 4:

$$
\begin{aligned}
& e\left(C h_{a}\right)=C h_{a}^{*}-C h_{a}(k) \text { is } Z \rightarrow C h_{a}^{*}-C h_{a}(k)=0 \rightarrow C h_{a}(k)=C h_{a}^{*} ; \\
& \Delta e\left(C h_{a}\right)=\left(C h_{a}^{*}-C h_{a}(k)\right)-\left(C h_{a}^{*}-C h_{a}(k-1)\right)<0 \text { is } N \rightarrow C h_{a}(k-1)-C h_{a}(k)<0 \\
& \text { and } C h_{a}(k)>C h_{a}(k-1) .
\end{aligned}
$$

Conclusion: $C h_{a}(k)$ records an increase value at time $(k)$ from time $(k-1)$ and is equal to initial reference expense $C h_{a}^{*}$. This means that the impact of this increase will cause a reduction in economic benefits, which means that $B_{e}(k)<B_{e}(k-1)$ and hence $\Delta B_{e}(k)<N$.

Rule no. 5:

$e\left(C h_{a}\right)=C h_{a}^{*}-C h_{a}(k)$ is $Z \rightarrow C h_{a}^{*}-C h_{a}(k)=0 \rightarrow C h_{a}(k)=C h_{a}^{*}$;

$\Delta e\left(C h_{a}\right)=\left(C h_{a}^{*}-C h_{a}(k)\right)-\left(C h_{a}^{*}-C h_{a}(k-1)\right)=0$ is $Z \rightarrow C h_{a}(k-1)-C h_{a}(k)=0$

and $C h_{a}(k)=C h_{a}(k-1)$.

Conclusion: $C h_{a}(k)$ records the same value at time $(k)$ versus time $(k-1)$ and is the same as the initial reference expense $C h_{a}^{*}$. This means that the impact of this increase will cause a stagnation of the economic benefits which means that $B_{e}(k)=B_{e}(k-1)$ and hence $\Delta B_{e}(k)=Z$.

Rule no. 6:

$$
\begin{aligned}
& e\left(C h_{a}\right)=C h_{a}^{*}-C h_{a}(k) \text { is } Z \rightarrow C h_{a}^{*}-C h_{a}(k)=0 \rightarrow C h_{a}(k)=C h_{a}^{*} ; \\
& \Delta e\left(C h_{a}\right)=\left(C h_{a}^{*}-C h_{a}(k)\right)-\left(C h_{a}^{*}-C h_{a}(k-1)\right)>0 \text { is } N \rightarrow C h_{a}(k-1)-C h_{a}(k)>0 \\
& \text { and } C h_{a}(k)<C h_{a}(k-1) .
\end{aligned}
$$

Conclusion: $C h_{a}(k)$ records a decrease in value at time $(k)$ from moment $(k-1)$ and is the same as the initial reference expense $C h_{a}^{*}$. This means that the impact of this increase will result in an increase in economic benefits, which means that $B_{e}(k)>B_{e}(k-1)$ and hence $\Delta B_{e}(k)>Z$.

Rule no. 7:

$$
\begin{aligned}
& e\left(C h_{a}\right)=C h_{a}^{*}-C h_{a}(k) \text { is } P \rightarrow C h_{a}^{*}-C h_{a}(k)>0 \rightarrow C h_{a}(k)<C h_{a}^{*} \text {; } \\
& \Delta e\left(C h_{a}\right)=\left(C h_{a}^{*}-C h_{a}(k)\right)-\left(C h_{a}^{*}-C h_{a}(k-1)\right)<0 \text { is } N \rightarrow C h_{a}(k-1)-C h_{a}(k)<0 \\
& \text { and } C h_{a}(k)>C h_{a}(k-1) \text {. }
\end{aligned}
$$

Conclusion: $C h_{a}(k)$ records an increase value at time $(k)$ from time $(k-1)$ and is less than the initial reference expense $C h_{a}^{*}$. This means that the impact of this increase will cause a stagnation of economic benefits, which means that $B_{e}(k)=B_{e}(k-1)$ and hence $\Delta B_{e}(k)=Z$.

Rule no. 8:

$$
\begin{aligned}
& e\left(C h_{a}\right)=C h_{a}^{*}-C h_{a}(k) \text { is } P \rightarrow C h_{a}^{*}-C h_{a}(k)>0 \rightarrow C h_{a}(k)<C h_{a}^{*} ; \\
& \Delta e\left(C h_{a}\right)=\left(C h_{a}^{*}-C h_{a}(k)\right)-\left(C h_{a}^{*}-C h_{a}(k-1)\right)=0 \text { is } Z \rightarrow C h_{a}(k-1)-C h_{a}(k)=0 \\
& \text { and } C h_{a}(k)=C h_{a}(k-1) .
\end{aligned}
$$

Conclusion: $\mathrm{Ch}_{a}(k)$ records the same value at time $(k)$ versus time $(k-1)$ and is less than the initial reference expense $C h_{a}^{*}$. This means that the impact of this increase will result in an increase in economic benefits, which means that $B_{e}(k)>B_{e}(k-1)$ and hence $\Delta B_{e}(k)>P$. 
Rule no. 9:

$$
\begin{aligned}
& e\left(C h_{a}\right)=C h_{a}^{*}-C h_{a}(k) \text { is } P \rightarrow C h_{a}^{*}-C h_{a}(k)>0 \rightarrow C h_{a}(k)<C h_{a}^{*} ; \\
& \Delta e\left(C h_{a}\right)=\left(C h_{a}^{*}-C h_{a}(k)\right)-\left(C h_{a}^{*}-C h_{a}(k-1)\right)>0 \text { is } P \rightarrow C h_{a}(k-1)-C h_{a}(k)>0 \\
& \text { and } C h_{a}(k)<C h_{a}(k-1) .
\end{aligned}
$$

Conclusion: $C h_{a}(k)$ records a decrease in the value at time $(k)$ from moment $(k-1)$ and is lower than the initial reference expense $C h_{a}^{*}$. This means that the impact of this increase will result in an increase in economic benefits, which means that $B_{e}(k)>B_{e}(k-1)$ and hence $\Delta B_{e}(k)>Z$.

The inference operation of the fuzzy rule-based of the controller which is elaborated to detect the asset's financial sustainability risk is of the type min-max. The formula of the implication relation used for the mathematical description of each rule from the fuzzy rule-based is of type min - MAMDANI. The aggregating method of the partial conclusions generated by the rules in the fuzzy rule-based is of type max.

The final step of the fuzzy controller is to determine the value of the output variable obtained after the fuzzy inference operation. This operation is known in the literature as the centroid deafuzzification or the Center of Aria (COA) method. The results obtained are a control curve without sudden variations. The formula for determining the value of the output variable based on the output fuzzy set is as follows (Figure 1):

- For continuous variables:

- For discrete variables:

$$
\Delta B e^{*}=\frac{\int_{-p \%}^{+p \%} \Delta B e \mu_{\Delta B e^{*}}(\Delta B e) d \Delta B e}{\int_{-p \%}^{+p \%} \mu_{\Delta B e^{*}}(\Delta B e) d \Delta B e} .
$$

$$
\Delta B e^{*}=\frac{\sum_{-p \%}^{+p \%} \Delta B e \mu_{\Delta B e^{*}}(\Delta B e)}{\sum_{-p \%}^{+p \%} \mu_{\Delta B e^{*}}(\Delta B e)} .
$$

The output variable value of the fuzzy controller for $\left(\Delta B e^{*}\right)$ gives us information about the variable trend when there is a change in the value of the input variables: $\left(C h_{a}\right)$ and $\left(\Delta C h_{a}\right)$.

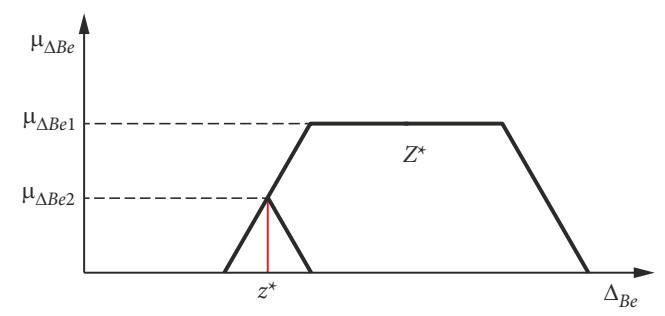

Figure 1 . The output fuzzy set $Z^{*}$ for establishing the output variable 


\section{Validation of the results obtained with the fuzzy controller}

The output variable of the fuzzy controller sets the economic benefit variation ranges $(\triangle B e)$ when a change in the value of the input variables mentioned above occurs. These output values obtained for the fuzzy variable must be converted to values that can be used to analyze the asset financial sustainability risk. From the fuzzy rule base of the fuzzy controller can be distinguished three situations namely:

Situation 1: When $B e>0$ or $B e_{t+1}-B e_{t}>0$ results that $B e_{t+1}>B e_{t}$. This assumes that the economic benefits increase from time to time and the financial sustainability risk is significantly reduced. This risk reduction is possible either as a result of the use of assets under appropriate technical conditions or as a result of compliance with the technical maintenance program. The financial sustainability risk with converted and discrete values will be determined as follows:

$$
\operatorname{ers} f_{a}=\frac{\frac{\Delta B e(1+p \% \Delta B e)}{B e}}{\frac{\Delta C h_{a}\left(1+p \% \Delta C h_{a}\right)}{C h_{a}}} .
$$

Situation 2: When $B e=0$ or $B e_{t+1}-B e_{t}=0$ results that $B e_{t+1}=B e_{t}$. This assumes that the economic benefits are constant from one period to another. This situation, though rarely, catch the influence of the asset's operating expenses variation on the financial sustainability risk. In this situation the financial sustainability risk with values converted from the controller will be determined with the relation:

$$
\operatorname{ers} f_{a}=\frac{\frac{\Delta B e}{B e}}{\frac{\Delta C h_{a}\left(1 \pm p \% \Delta C h_{a}\right)}{C h_{a}}} .
$$

Situation 3: When $\Delta B e<0$ and $B e_{t+1}-B e_{t}<0$ results that $B e_{t+1}<B e_{t}$. This implies a diminution of the economic benefits from one period to another. The situation may indicate exposure to financial sustainability risk, either as a result of the decrease in production capacity due to technical reasons, or as a result of the uncontrolled increase in the operating expenses. Regardless of the nature of these causes, assets must be carefully monitored to avoid situations where asset investments become economically inefficient. The financial sustainability risk with values converted from the controller will be as follows:

$$
\text { ersf } f_{a}=\frac{\frac{\Delta B e(1-p \% \Delta B e)}{B e}}{\frac{\Delta C h_{a}\left(1 \pm p \% \Delta C h_{a}\right)}{C h_{a}}} .
$$

\section{Simulation of the Mamdani Fuzzy Controller in the financial sustainability risk analysis for ski slopes}

The simulation was conducted for a company that manages a ski area in the Southern Carpathians of Romania. The focus was pointed on tangible assets such as artificial snow installations and Ratrak equipment. 
The MAMDANI fuzzy controller developed works having as input variables the operating expenses of the asset $\left(C h_{a}\right)$ and their variation $\left(\Delta C h_{a}\right)$. For the operating costs $\left(C h_{a}\right)$ where established variation ranges from $(-50 \%,+50 \%)$. This means that two asset life cycles have been tested, namely: a period during which the operating expenses decrease (a good asset behavior) and another period when the asset operating expenses grow with impact on economic benefits. Such a period shall be recorded, in particular, when the asset no longer complies with the technical conditions of operation. During these periods, technical defects are frequent.

For the operating costs variation $\left(\Delta C h_{a}\right)$ where also established variation ranges from $(-30 \%$ to $+30 \%)$. The change in operating expenses between two periods $(k)$ and $(k+1)$ was considered positive, respectively: $\left(\Delta C h_{a}>0\right)$ and then negative $\left(\Delta C h_{a}<0\right)$. Two situations are recorded: operating expenses that increase between two consecutive periods with a direct impact on reducing economic benefits and operating expenses that diminish from one period to another with an impact on increasing the economic benefits and reducing the financial sustainability risk. Two scenarios were simulated:

Table 5. The first fuzzy controller simulation with progressive increase of the variation intervals

\begin{tabular}{|c|c|c|c|}
\hline$C h_{a} \%$ & $\Delta C h_{a} \%$ & $\triangle B N \%$ & $\left(e_{s r f}\right)$ \\
\hline-50 & -30 & -20.9 & 1.13 \\
\hline-45 & -27 & -20.2 & 1.09 \\
\hline-40 & -24 & -19.5 & 1.06 \\
\hline-35 & -21 & -18.9 & 1.03 \\
\hline-30 & -18 & -18.3 & 1.00 \\
\hline-25 & -15 & -17.8 & 0.97 \\
\hline-20 & -12 & -17.3 & 0.94 \\
\hline-15 & -9 & -16.9 & 0.91 \\
\hline-10 & -6 & -16.6 & 0.89 \\
\hline-5 & -3 & -16.4 & 0.86 \\
\hline 0 & 0 & -1.6 & 0.98 \\
\hline 5 & 3 & -1.61 & 0.96 \\
\hline 15 & 6 & -1.67 & 0.93 \\
\hline 20 & 9 & -1.72 & 0.90 \\
\hline 25 & 12 & -1.8 & 0.88 \\
\hline 30 & 15 & -1.9 & 0.85 \\
\hline 35 & 18 & -2.04 & 0.83 \\
\hline 40 & 21 & -5.71 & 0.87 \\
\hline 45 & 24 & -2.5 & 0.79 \\
\hline 50 & 27 & -1.82 & 0.77 \\
\hline
\end{tabular}

Table 6. Simulation of the fuzzy controller no. 2 with alternating variation intervals

\begin{tabular}{|c|c|c|c|}
\hline$C h_{a} \%$ & $\Delta C h_{a} \%$ & $\triangle B N \%$ & $\left(e_{s r f}\right)$ \\
\hline-45 & -25 & -23.5 & 1.02 \\
\hline-30 & -25 & -22.7 & 1.03 \\
\hline-15 & -10 & -19.2 & 0.90 \\
\hline-5 & -10 & -17.8 & 0.91 \\
\hline-25 & 15 & 19.2 & 1.04 \\
\hline-15 & 30 & 0 & 0.77 \\
\hline-5 & 0 & -1.6 & 0.98 \\
\hline-5 & 10 & 17.8 & 1.07 \\
\hline-5 & 20 & 20.9 & 1.01 \\
\hline 5 & -25 & -1.42 & 1.31 \\
\hline 10 & -20 & -4.93 & 1.19 \\
\hline 20 & -5 & 18.3 & 1.25 \\
\hline 40 & -10 & 22.3 & 1.36 \\
\hline 50 & -25 & 0 & 1.33 \\
\hline 0 & 20 & -1.82 & 0.82 \\
\hline 10 & 5 & -1.67 & 0.94 \\
\hline 20 & 5 & -1.9 & 0.93 \\
\hline 40 & 5 & -4.93 & 0.91 \\
\hline 50 & 20 & 0 & 0.83 \\
\hline 5 & 5 & -1.64 & 0.94 \\
\hline
\end{tabular}


The first scenario, with the first fuzzy controller, consists in input variables that progressively change. The variation ranges of the input variables in the fuzzy controller were split using local gradients in 5-point subintervals, being formed 20 pairs of values presented in the table below. The tangible asset taken into account generates operating expenses of 4.000 per month and an operational income of 5.000 per month with a net benefit of 1.000 per month (Table 5).

Variation ranges were divided into two categories, namely:

Negative variation ranges with decreasing operating costs $\left(C h_{a}<0\right)$ and decreasing operating costs variations $\left(\Delta C h_{a}<0\right)$. This means that operating costs are higher than those originally established $\left(C h_{a}^{*}\right)$, but also from one period to the next, respectively $C h_{a}(k)>C h_{a}(k-1)$. The direct consequence is the diminution of the economic benefits obtained with the asset over its lifecycle. On these variation ranges where the asset's operating expenses can register values within the range $C h_{a} \in[0 \%,-50 \%]$ and the operating expenses variation from one period to the next may register values in the range $\Delta C h_{a} \in[0 \%,-30 \%]$, the variance of the economic benefits obtained with the fuzzy controller can take values in the range $\Delta B e \in[-16.4 \%, 20.4 \%]$. Greater variations in economic benefits than those generated using fuzzy controller determine the emergence of the financial sustainability risk, with immediate consequences on the efficiency of investments regardless of their nature.

Positive variation ranges of operating expenses $\left(C h_{a}>0\right)$ and positive operating costs variations $\left(\Delta C h_{a}<0\right)$. This assumes that operating costs are lower than those originally set $\left(C h_{a}^{*}\right)$ and decrease from one period to the next $C h_{a}(k)<C h_{a}(k-1)$. The immediate consequence is that there are insignificant variations in economic benefits from one operating period to another. The ranges of operating cost variation are between $C h_{a} \in[0 \%,+50 \%]$, while the operating cost variation range $\Delta C h_{a} \in[0 \%,+30 \%]$. The variation in economic benefits is in the range $\Delta B e \in[-1.61 \%,-5.71 \%]$. It can be argued that on these types of intervals the financial sustainability risk interferes in a small extent.

The conclusion is that it is possible to measure the asset financial sustainability risk at every moment of its operation. The deviation of the economic benefits from the initial value is a measure of the intensity of this type of risk. The reliability of the fuzzy controller can be measured with the help of the indicator $\left(e_{s r f}\right)$, whose values are closer to 1 , fact that confirms the usefulness of the fuzzy rule base and of the controller (Figure 2).

The second simulation scenario is the one in which are alternating ranges with positive values and ranges with negative values. The variation ranges of the input variables were subtracted by $5 \%$, in order to draw conclusions about the economic benefits evolution and $C h_{a} \in[0 \%, \pm 50 \%], \Delta C h_{a} \in[0 \%, \pm 30 \%]$. The results are presented in the Table 6.

Thus four value ranges are distinguished:

a) Negative variation interval, in which both $\left(C h_{a}<0\right)$ and $\left(\Delta C h_{a}<0\right)$ record negative values assuming that $\Delta B e \in[-17.8 \%,-23.5 \%]$. Beyond these economic benefits variations, it is possible that the company's investments in assets to be made under conditions of economic inefficiency, so that the asset needs to be replaced;

b) Negative variation interval for operating costs $\left(C h_{a}<0\right)$ and positive values for $\left(\Delta\left(\Delta C h_{a}>0\right)\right.$. The economic significance of these variations shows that operating costs are higher than those initially recorded, however they are decreasing from one 


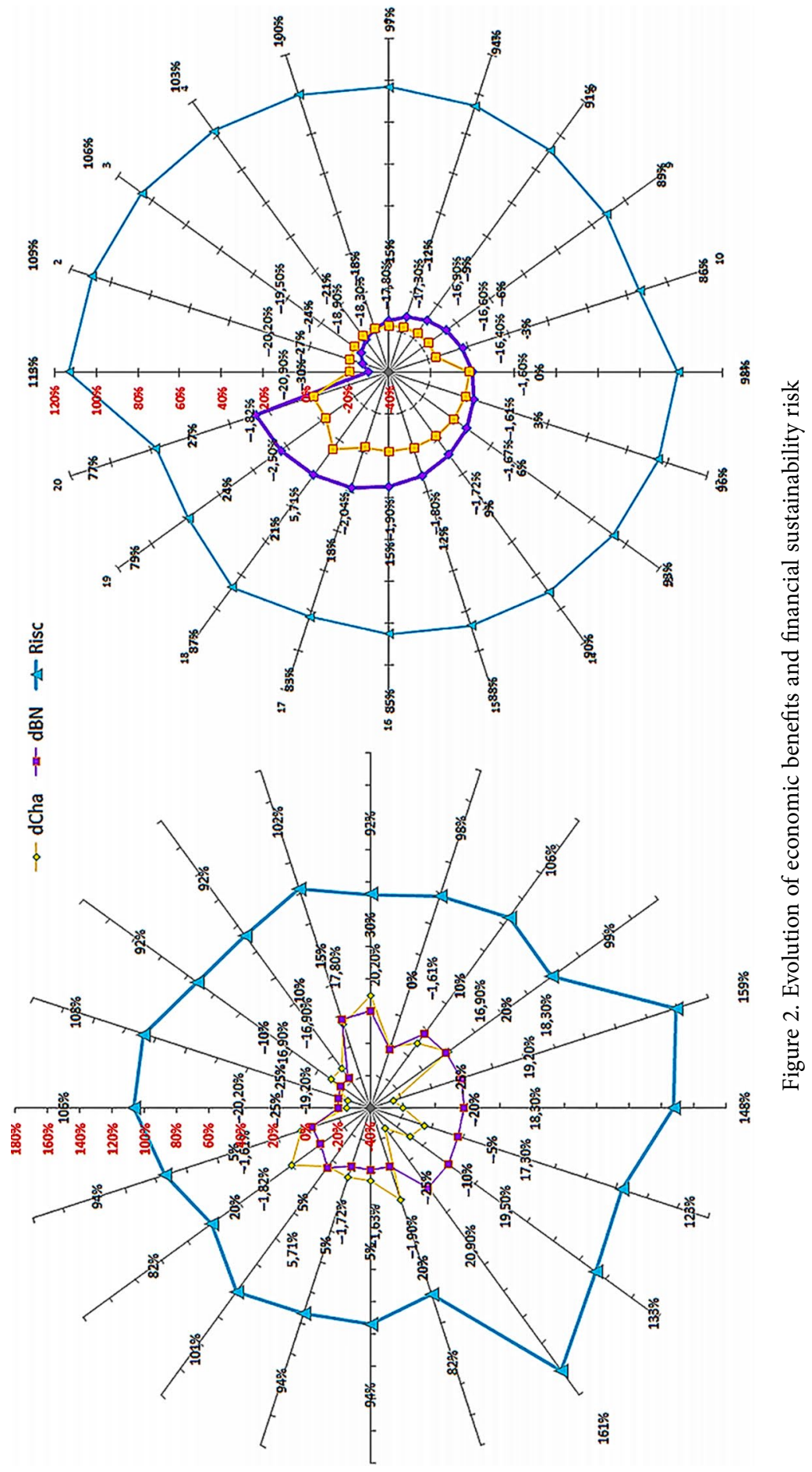


period to the next. The immediate consequence is that the change in economic benefits is positive, which implies a reduction in the financial sustainability risk.

c) Positive variation interval for operating costs $\left(C h_{a}>0\right)$ and negative values for $\left(\Delta\left(\Delta C h_{a}<0\right)\right.$. The economic significance of these variations is that operating costs are lower than those initially recorded, while the same categories of expenditure are increasing from one period to the next. The variation in economic benefits can be positive or negative. For periods in which the change in economic benefits is positive, the financial sustainability risk decreases, while negative variations in economic benefits increase the financial sustainability risk.

d) Positive variation interval, for both $\left(C h_{a}>0\right)$ and $\left(\Delta C h_{a}>0\right)$. In this situation, the variation in economic benefits remains almost unchanged, which confirms the reliability of the elaborated fuzzy controller. The recovery periods of the invested capital are in line with the expectations of the company's shareholders.

The MAMDANI fuzzy controller was tested on the assets of the company managing the skiing area, especially those assets that are essential to the business (Figure 3). Based on the technical capacity of assets, were considered in the analysis the operational expenses and revenues generated for 12 periods of time.

It could be noticed that the real net benefits of the company are above the values generated by the MAMDANI fuzzy controller for the first two periods, illustrating that the company is not exposed to the financial sustainability risk. For the others 10 periods of time the net benefits values are situated below the optimal values calculated by the fuzzy controller, indicating a susceptible risk area and thus requiring management intervention in real-time.

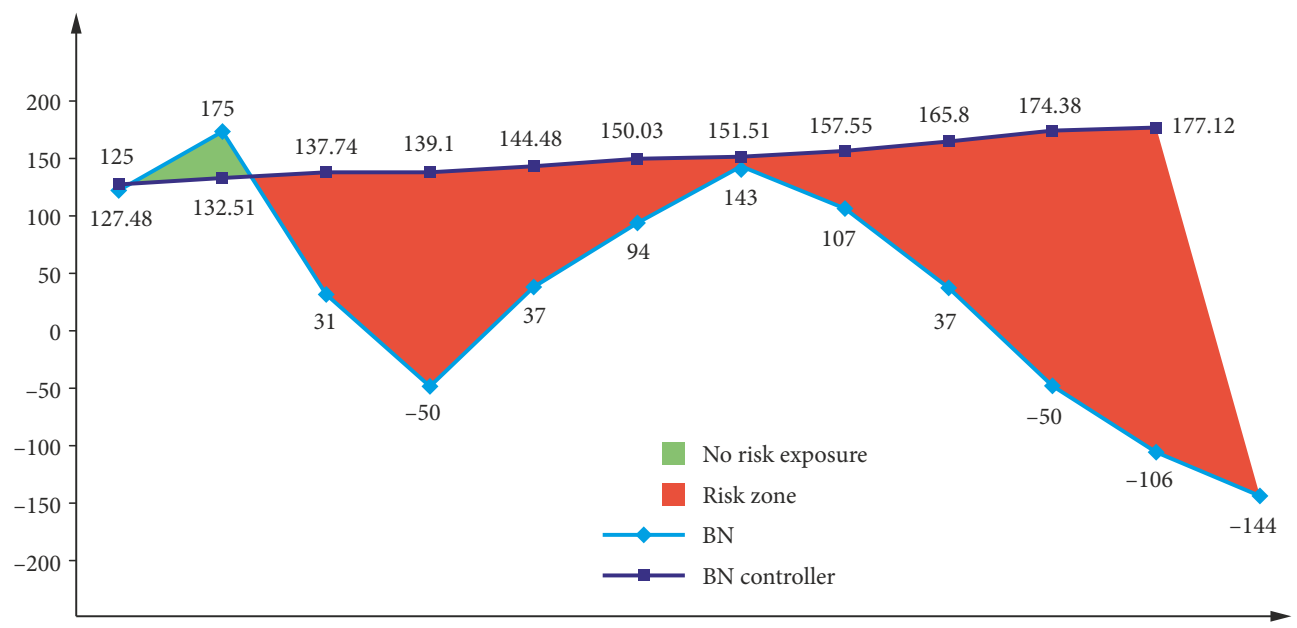

Figure 3. Testing the MAMDANI fuzzy controller on the artificial snow installations and Ratrak equipment 


\section{Conclusions}

Asset regardless of their nature need to be analyzed based on the financial sustainability risk defined as the risk category in which the company's investments in that asset are no longer warranted from the economic efficiency point of view. To measure and identify this risk category, a fuzzy controller has been developed that is based on two input variables that are determinant for any asset, namely: the operating costs and the operating cost variations between two time points. The exit variable was established to be the variation in the asset economic benefits considered to be important in defining the asset financial sustainability. The controller's operation identifies four categories of important situations, namely:

Situation no. 1: Negative operating costs $\left(C h_{a}<0\right)$ and negative operating cost variations $\left(\Delta C h_{a}<0\right)$. The economic significance of this situation indicates that the operating expenses of the asset are higher than the initial operating expenses $\left(C h_{a}>C h_{a}^{*}\right)$, but also that these spending categories are higher from one period to another $C h_{a}(k)>C h_{a}(k-1)$. The impact on economic benefits is negative $(\Delta \mathrm{Be}<0)$, which implies an increase in the financial sustainability risk.

Situation no. 2: Positive operating costs $\left(C h_{a}>0\right)$ and negative operating cost variations $\left(\Delta C h_{a}<0\right)$. The economic significance of this situation indicates that the operating costs are lower than the initial operating expenses $\left(C h_{a}<C h_{a}^{*}\right)$ but still increasing from one period to another $C h_{a}(k)>C h_{a}(k-1)$. The impact on economic benefits is zero $(\Delta \mathrm{Be}=0)$, while keeping the financial sustainability risk under control.

Situation no. 3: Negative operating costs $\left(C h_{a}<0\right)$ and positive operating cost variations $\left(\Delta C h_{a}>0\right)$. This situation reflects that the operating costs are higher than the initial expenses $\left(C h_{a}>C h_{a}^{*}\right)$ but still decreasing from time to time $C h_{a}(k)<C h_{a}(k-1)$. The impact on economic benefits is zero $(\Delta \mathrm{Be}=0)$, while keeping the financial sustainability risk under control.

Situation no. 4: Positive operating costs $\left(C h_{a}>0\right)$ and positive operating cost variations $\left(\Delta C h_{a}>0\right)$. This situation indicated that operating expenses are lower than the initial operating expenses $\left(C h_{a}<C h_{a}^{*}\right)$ while the change in operating expenses from one period to another is decreasing $\left(C h_{a}(k)<C h_{a}(k-1)\right)$. The impact on economic benefits is positive $(\Delta \mathrm{Be}>0)$, with the reduction of the financial sustainability risk.

The major advantage of the fuzzy controller is that it measures the financial sustainability of the asset at every desired time. Any value recorded by the economic benefit, outside the range of variation indicated by the MAMDANI fuzzy controller, indicates that the asset is exposed to financial sustainability risk and generates investments that no longer add value to the company. For assets chains, the use of the fuzzy controller involves measuring the individual financial sustainability risk of each asset, in order to determine which of the assets should be replaced as a result of their inefficiency.

\section{Funding}

No grants were used for the research and publication of this article. 


\section{Author contributions}

The paper is a result of a collaborative work. Bradea Ioana and Diana Sabău-Popa did the literature review, Bolos Marcel and Bradea Ioana worked at the methodology, Boloș Marcel and Ilie Laurențiu did the valorification the results and the simulation. Boloș Marcel, Bradea Ioana and Ilie Laurențiu prepare the first draft and Diana Sabău-Popa worked at the abstract, language and final revisions.

\section{Disclosure statement}

The authors declare no conflict of interest.

\section{References}

Ahn, K. K., \& Truong, D. Q. (2009). Online tuning fuzzy PID controller using robust extended Kalman filter. Journal of Process Control, 19(6), 1011-1023. https://doi.org/10.1016/j.jprocont.2009.01.005

Ambrose, B. W., \& Megginson, W. L. (1992). The role of asset structure, ownership structure, and takeover defenses in determining acquisition likelihood. Journal of Financial and Quantitative Analysis, 27(4), 575-589. https://doi.org/10.2307/2331141

Ardeleanu-Popa, C., \& Miheş, C. (2007). Aspects regarding the criminal responsibility of the administrator. The interest of the company versus personal interest of its administrators. In Stiinte economice (Vol. XVI(1), pp. 30-33). The Annals of the University of Oradea, Economic Sciences, Oradea, Romania.

Bolos, M. I., \& Sabau-Popa, D. C. (2017). Developing an adaptive fuzzy controller for risk management of company cash flow. International Journal of Fuzzy Systems, 19(2), 414-422. https://doi.org/10.1007/s40815-016-0159-Z

Cordon, O. (2011). A historical review of evolutionary learning methods for Mamdani-type fuzzy rulebased systems: designing interpretable genetic fuzzy systems. International Journal of Approximate Reasoning, 52(6), 894-913. https://doi.org/10.1016/j.ijar.2011.03.004

Galbreath, J. (2005). Which resources matter the most to firm success? An exploratory study of resourcebased theory. Technovation, 25(9), 979-987. https://doi.org/10.1016/j.technovation.2004.02.008

Galichet, S., \& Foulloy, L. (1995). Fuzzy controllers - synthesis and equivalences. IEEE Transactions on Fuzzy Systems, 3(2), 140-148. https://doi.org/10.1109/91.388169

Harris, J. (2017). Increasing sustainability in small utilities through GIS and asset management. In Pipelines 2017: Condition assessment, surveying and geomatics, Phoenix, Arizona, USA (pp. 187-198). American Society of Civil Engineers. https://doi.org/10.1061/9780784480885.018

Huang, Y. P., Singh, A., Liu, S. I., Wu, S. I., Quoc, H. A., \& Sereter, A. (2018). Developing transformed fuzzy neural networks to enhance medical data classification accuracy. International Journal of Fuzzy Systems, 20(6), 1925-1937. https://doi.org/10.1007/s40815-018-0503-6

Kaufmann, A. (1963). Methods and models of operations research. New Jersey, USA: Prentice-Hall Publishing.

Krishankumar, R., Ravichandran, K. S., Premaladha, J., Samarjit, K., Zavadskas, E. K., \& Antucheviciene, J. (2018). A decision framework under a linguistic hesitant fuzzy set for solving multi-criteria group decision making problems. Sustainability, 10(8), 1-21. https://doi.org/10.3390/su10082608 
Liu, Z. F., Chen, Q. R., \& Xie, H. L. (2018). Influence of the farmer's livelihood assets on livelihood strategies in the western mountainous area, China. Sustainability, 10(3), 1-12. https://doi.org/10.3390/su10030875

Mannasoo, K., \& Maripuu, P. (2015). Company performance, investment decision and cyclical sensitivity: a dynamic estimation on company microdata. Eastern European Economics, 53(1), 25-38. https://doi.org/10.1080/00128775.2015.1033318

Mann, G. K. I., Hu, B. G., \& Gosine, R. G. (1999). Analysis of direct action fuzzy PID controller structures. IEEE Transactions on Systems Man and Cybernetics Part B-Cybernetics, 29(3), 371-388. https://doi.org/10.1109/3477.764871

Mohan, B. M., \& Sinha, A. (2008). Analytical structure and stability analysis of a fuzzy PID controller. Applied Soft Computing, 8(1), 749-758. https://doi.org/10.1016/j.asoc.2007.06.003

Pontryagin, L. S., Boltyanskii, V. G., Gamkrelidze, R. V., \& Mishchenko, E. F. (1962). The mathematical theory of optimal processes. New-York, USA: Interscience Publishers, John Wiley \& Sons.

Precup, R. E., \& Hellendoorn, H. (2011). A survey on industrial applications of fuzzy control. Computers in Industry, 62(3), 213-226. https://doi.org/10.1016/j.compind.2010.10.001

Qin, Y., Sun, L., Hua, Q., \& Liu, P. (2018). A fuzzy adaptive PID controller design for fuel cell power plant. Sustainability, 10(7), 1-15. https://doi.org/10.3390/su10072438

Reichardt, C. L. (2006). Due diligence assessment of non-financial risk: prophylaxis for the purchaser. Resources Policy, 31(4), 193-203. https://doi.org/10.1016/j.resourpol.2007.01.002

Terborgh, G. (1949). Dynamic equipment policy. New-York, USA: McGraw-Hill.

Wang, M., Chen, B., \& Dai, S. L. (2007). Direct adaptive fuzzy tracking control for a class of perturbed strict-feedback nonlinear systems. Fuzzy Sets and Systems, 158(24), 2655-2670. https://doi.org/10.1016/j.fss.2007.06.001

Wu, D., Yang, Z., Wang, N., Li, C., \& Yang, Y. (2018). An integrated multi-criteria decision-making model and AHP weighting uncertainty analysis for sustainability assessment of coal-fired power units. Sustainability, 10(6), 1-27. https://doi.org/10.3390/su10061700

Yu, W., \& Li, X. O. (2004). Fuzzy identification using fuzzy neural networks with stable learning algorithms. IEEE Transactions on Fuzzy Systems, 12(3), 411-420.

https://doi.org/10.1109/TFUZZ.2004.825067 
